\title{
Promoting Dialogue in a Saudi University: An Empirical Study
}

\author{
Adel Bawazeer \\ University of Stirling, Scotland \\ King Abdulaziz University, Jeddah, Saudi Arabia
}

\begin{abstract}
This paper investigates whether a group of university teachers and students was enthusiastic about engaging in dialogue in their classrooms and whether they had varied responses to the idea of applying the concepts of dialogue to a Saudi university textbook. Like many other universities, King Abdulaziz University adopted an "Islamic Culture" textbook for courses taught by academic staff. In this study, the sample consisted of students who were taught it and who agreed to take part in semi-structured interviews. The findings showed that the concepts of dialogue could be integrated in a university textbook and that teachers and students were enthusiastic enough to take active roles in the dialogue which ensued in their classes. However, while all the participants agreed that some of their concepts of dialogue could be endorsed by the textbook and thus integrated, they had different views on what should take priority among these concepts and their relative importance. These differences may relate to the level of experience and knowledge available to each respondent.
\end{abstract}

\section{Introduction}

From various references, it appears that one of the functions of dialogue is to allow the opinions of the parties to the dialogue to be exchanged, which encourages both parties to listen, ask questions, discuss the ideas thrown up and to think deeply in order to reach creative outcomes (Swidler, 2012; [8]. In higher education in Saudi Arabia, it is noted that dialogue has among its aims the effect of integrating speakers into the university system and thus preparing qualified and competent citizens by training and by reorientation courses to keep pace with new developments [37]. This invisible effect is necessary to combat the otherwise limited academic freedom in Saudi universities [2].

This paper sought to integrate the potential of dialogue in the higher education textbook used in Saudi Arabia. In this area the role of dialogue in the exchange of knowledge has become more important, implying a new relationship between teachers and students in a social and cooperative environment [18], [19].

I had many reasons for wanting to examine this. In previous research, I had found that students had several criticisms of the academic aspects of the "Islamic Culture" book that could be approached through dialogue. However, in Saudi culture, the use of dialogue as a means of communication between people has only weak or medium value [22]. This means that people are not properly qualified to engage in dialogue and thus that it is urgent to spread a regard for dialogue in the culture. Among the many recognised methods for permeating a culture, education is considered to be instrumental. Pieczka et al. [33], for instance, provide three models for engaging in dialogue, one of which is through education, in particular when it is known that teachers can play a part in improving students' capacities for dialogue [5].

The present paper investigates whether the university teachers and students in King Abdulaziz University were enthusiastic over engaging in dialogue in their classrooms and whether they had varied responses to the question of applying their concepts of dialogue to a Saudi university textbook.

\section{Background}

\subsection{Dialogue in Saudi Arabia}

The main question here is why dialogue is important in Saudi Arabia, at a time when the country is still 'mono-cultural' in character: the whole population follows one religion, uses one language, has one government and has no political parties. To begin with, we should recognize that pluralism in Saudi Arabia can be identified through differences between the perspectives of a range of religious scholars on the regulations for daily life and the methods of implementing them. The space between these perspectives increases according to the influence of other perspectives, taken by different groups of conservative scholars, liberal reformers and Islamic thinkers [44].

The importance of dialogue in Saudi Arabia is found in the engendering of a dialogue culture, which yet shows sensitivity to and some 
understanding of religious values and the value of national unity [23]. Dialogue is presumed to play an essential role in this issue, in addressing such extraneous matters as violence, blasphemy and terrorism, which have affected the stability and security of the country for some time [28].

With this in mind, dialogue in Saudi Arabia is being promoted with a view to training people to engage in dialogue as part of their everyday life, providing them with a way of thinking and a clearer method of expression so as to deal better with the variations in culture and civilisation now impinging on Arab countries from all over the world [34]. Dialogue, in this way, can contribute to improve people's capacity to enter into public conversations on social or national events and to build good relations and full interaction with others to strengthen the nation's identity [42].

Training in productive conversations and collective thinking is needed to encourage dialogue between people in society as they face the challenges to their community and seek solutions; the need for dialogue will increase as the volume of challenges increases [41]. Currently, Saudi society faces many modern challenges to its identity and needs to clarify its religious views before applying any of the suggested solutions.

Different examples of issues for the Saudi community issues can be provided, such as women's rights; and issues arising from deviant ideas on terrorism, atonement and bombing could be added. These challenges will require extensive dialogue if religious, social and political consensus is to be attained.

Given that the whole population of the Kingdom is Muslim, religion is central to life and is also the main referent for the issues and challenges faced by the people. In this sense, the function of dialogue for them relates intimately to their religious understanding, its application and its effect on the culture of their society. This puts the spotlight on dialogue regarding the local challenges, under Islam, to social life, identity and modernity [24].

While the discussion above may encourage the use of dialogue, certain obstacles to it may influence the project under review. Not enough social research has been done to identify the main challenges to Saudi society, and too little attention has been paid to highly important points which emerge in everyday life; moreover. other important areas are also worth discussing, such as young people's needs, unemployment, social services, concepts of citizenship and variations in the individual capacities of individuals. All these may be seen as barriers to the successful use of dialogue in Saudi society.

The above concerns reveal the central issues in the make-up of the Saudis, showing that achieving better communication and improved ability to proceed by dialogue may require training those who take part in dialogue conferences to be more capable of reaching useful outcomes. Thus, it appears that the educational field could have an unrivalled position and play an essential role in increasing awareness amongst people, educating them and teaching them to be more capable in pursuing dialogue.

\subsection{University Curriculum}

Those who work in higher education have become more interested in designing the curriculum so that it engages students in learning effectively [9], [13]. However, different aspects may need to be considered when designing curriculums for higher education functions, bearing in mind the changes in these functions. In the past the functions of the university were focused on knowledge as such, pure truth, philosophy and research, whereas professional education and social service, job requirements are currently the essential factors for universities [17].

Rhodes identifies many functions in modern university: creating new knowledge, finding ways to apply knowledge, supporting research, encouraging inquiry and study, preparing citizens, training workers for demanding jobs, enabling individuals to understand the world [36]. These reviews help us to understand the functions of modern universities and to design suitable university curriculums. The latter requires due consideration to be given to such important points as students' knowledge and experience; their prior experience of writing and reading and also, in this instance, of speaking; the need to attract students' attention; ease of use in preparing course reading lists, lecture notes and course materials; space for discussing some of the less obvious terms; and simplicity of expression [26].

At Assiut University, Ahmad and Alwan suggest that higher education should transfer the theoretical to the practical and motivate students to think, brainstorm and discuss, to connect them to community issues, to encourage them to learn about teamwork, to guide them to other sources of available knowledge and at the same time to be appropriate to their level in terms of language, style, presentation and student ability [1].

Dialogue has an ongoing integrative relationship with education because the knowledge to be transmitted is built upon certain processes associated with dialogue [25]. However, the main question for this project is 'What activities can stimulate the dialogue in the classrooms of the university in question?' 


\subsection{Dialogue and Higher Education}

Every country has its own specific educational system, independent of other countries. The guides to the curriculum material designed for higher education include its aims, learning approaches and methods, subjects, resources and course assessment [30]. Some countries, such as Saudi Arabia, consider textbooks which contains the course outline to be a principal resource. For such countries, textbooks are deemed essential in higher education as the principal sources of knowledge and skills, often with the particular function of turning students' attention towards current issues in society and ways to address them [3].

The higher education curriculum, as a consequence, may need the authors of textbooks to take extreme care; they must nourish the knowledge, general experiences, needs and skills of students through writing, reading, listening and speaking. The textbook must explain the main concepts of the course and the community issues raised by them and must also provide room for discussion [26].

Among the ideas that can motivate students to engage in active dialogue is to integrate them in the project of designing of the university's curriculum, called 'student participation in curriculum design' [9]. Although there are many cautions surrounding the idea of such participation and it is not clear what the criteria for participation should be as regards the students' background in higher education functions and the diversity of the perspectives between the students [35], [40], it is clear that there are some advantages in letting them join in.

For example, it can change their role from passive receptors into active ones and even active members of society [38], [45]; improve their sense of responsibility for their own learning and continued education [39]; and work to clarify the different meanings of freedom and critical thinking [4], [29]. The influence of their participation will be reflected in their evaluating, improving and making a positive impact on curriculum and course assessment [12], [32].

Furthermore, in order to improve the dialogue skills among students, dialogue should be encouraged every time a university textbook deals with topics which are directly relevant to society. These topics connect the students and teachers in any classroom over the most important civic, social and ethical problems [10].

However, a textbook is not enough to improve the students' dialogue skills unaided. The teacher's methodology, activities and educational aids, coupled with educational technology, must add their influence to complete the work. Dialogue in the classroom should become a more frequent feature, because such dialogue "allows students to reflect on their own thinking, to detail their own understanding, to listen to each other's ideas and to ask questions for clarification" [25]. Exercises to improve dialogue skills should take a leading role in classroom activities, although it has been argued that some teachers and students "have become so involved with delivering the curricula that we have failed to acknowledge how we deliver the curricula" [20]. In addition, classroom communication helps to ensure that every student is exposed to a range of ideas, by making these ideas the focal points of questions and enabling students to interact with them through dialogue [25]. By offering syllabuses that have been designed to develop their dialogue skills and related capacities [31], we involve education in their overall development. University teachers "can dramatically influence the extent and quality of learning for all students" [27].

\section{Methodology}

The principal aims of this paper were to conduct an investigation to assess the enthusiasm of the academic staff and students at King Abdulaziz University for engaging in dialogue within the classroom, as well as their different responses to the question of how to apply the concept of dialogue in the content of the "Islamic Culture" module. While the King Abdulaziz Centre for national dialogue has the huge project of promoting the culture and skills of dialogue in Saudi Arabia, a previous study resulted mainly in preventing any edition of the "Islamic culture" book at King Abdulaziz University from being based upon the success of the national dialogue or topics of discussion related to it [6]. Moreover, it has been discovered that none of the university textbooks had been designed to meet the demand of Saudi society and its government for the language of dialogue to be spread instead of the language of conflict [6]. This paper may therefore contribute as a main source of suitable ideas for inclusion in a university course book on "Islamic culture", one that could work and integrate itself within the vision of the government and satisfy the religious, intellectual and security needs of society.

In this undertaking, a qualitative research method was applied. Although some writers criticize qualitative approaches for being over-subjective [11], lacking in reliability and validity [41] and being time-consuming [7], qualitative methodology was judged the most appropriate for this project. The reasons of that, that this research sought to improve the curriculum by using interviews. This style of research can effectively work towards changing and improving the curriculum and educational policy [14] in addition to the style of analysing and coding the materials which have been transcribed from the interviews.

A group of questions was put to a number of academic staff and students in the semi-structured 
telephone interviews. Such interviews are flexible, enabling the interviewer to react to new and unexpected responses from participants, to ask new questions and to adapt the order of the questions to changes in the responses [21]. All the academic staff and students were selected as a sample for considering the module "Islamic Culture."

\section{Findings}

The findings of this research were something of a surprise. Most of the teachers and students enthusiastically supported the idea of promoting the concepts of dialogue, including its characteristic skills and behaviors, on the basis of the university textbook and the idea of student participation in designing the curriculum. They emphasised that, when space for dialogue is afforded in the classroom, the students themselves can contribute effectively to providing new knowledge, for example, stories, statistics and solutions to various problems. In line with this, both students and staff agreed that students can participate in designing the layout of the textbook, its colours and structures and also in designing the programmes of technological educational.

The interviews which were held on the theme of applying the concepts of dialogue in university classrooms have focused on possible ideas for supporting the university course on "Islamic Culture". The essential properties of dialogue were retained, in order to make it easy to apply them. In general, the participants concluded that the Islamic culture course and its textbook need to improve in three ways: in the teaching methods; by adding activities which relate to these methods; and in supporting students by mental exercises, questions and points which would encourage them to think. These educational features could change the pattern of teaching from a paradigm of transferring knowledge from teachers to students into one that encourages learning by engagement and greater effectiveness in the classroom. This could help the mental abilities of students to develop into thinking for themselves, criticism and analysis. Effective participation and an improved power of thinking could then be reflected in the students' becoming more active in the matter of dialogue, whether in the classroom or in the wider community.

However, the teachers judged that, while much of the knowledge in the textbook was significant, it was not appropriate for the students and their understanding, while the students themselves felt that the topics which it presented did not satisfy their needs or relate to their future interests. Consequently a group of respondents supported the idea of students' participating in future curriculum design. Another group of respondents criticised this idea, for several reasons. They reported that students' varied experiences and differing points of view could threaten the improvement of the curriculum and the attention of the participating students might not focus on the depth of knowledge that they could provide. However, they suggested that the students who took part in curriculum design should be elected from the students of distinction who should also work with expert academic staff.

\section{Discussion}

The results of the current study are shown through the participants' responses. They reveal a clear enthusiasm for engaging in dialogue in their "Islamic culture" classes. This was demonstrated by the benefits that they said would accrue from the textbook if it led to dialogue in the classroom and also from the common desire of all the participants to involve the students in preparing and improving their own curriculum. In fact, all of these could stimulate the dialogue in the classroom. It is believed, then, that to allow this could increase the sense of being responsible for curriculum design which leads to the creation of active students [38], [45], or active students in the education field [46].

Moreover, the participants provided some suggestions which could work to promote dialogue within the classroom. Most of these were consistent with those of Lea [26] and Ahmad and Alwan [1], such as training in listening skills, respecting speakers and their opinions, preparing evidence to support ideas, asking questions, diversifying ideas and offering and accepting positive criticism. The respondents thought also that it would have been helpful if these suggestions had been incorporated in the Islamic studies textbook and applied in the classrooms, thereby giving the students experience of being active in the field of dialogue.

In this regard, some current issues are important for all young people, including students in Saudi Arabia, such as finding and applying for a job, work skills, the value of working, unemployment, citizenship, a sense of belonging, modernity, identity, morals, women's issues and rights in Saudi Arabia, inviting non-Muslims to Islam, Westernisation and the correct view of Jihad. These social and civic issues could stimulate dialogue in the classroom [10].

However, teaching methods are key to encouraging dialogue in class. Many teaching methods are available for encouraging greater involvement in dialogue: asking questions, citing active social issues and swapping and discussing ideas [15], [31]. Therefore, the university course should seek to ensure that the finished text is suitable for students in terms of their age, needs, thinking level and interests [10]; [26].

On the idea of students' participation in designing the curriculum, the respondents were to a large 
extent contrasted. Respondents seem worried by the diversity of students' backgrounds and experiences, as well as the cognitive, intellectual and cultural differences which might result in an unworkable diversity of views [35], [40]. The authors agree with Lea [26] on the importance of experiences and background in textbook design. However, none of them discusses whether such diversity can enrich classroom communication or dialogue, a fact which may relate to the understanding of the roles available in dialogue or the concept of students' participation [35], [39].

\section{Conclusion}

To sum up, it appears that the university environment is ready to promote dialogue and both teachers and students are also enthusiastic about engaging in dialogue in class. It appears, too, that students' participation by dialogue in the classroom or in the discussions held by textbook-makers can make an impact on creating, improving or evaluating a university textbook

This is a great opportunity to take the advantages of this desire on the part of teachers and students by allocating enough space, projects and activities to dialogue. The content of the "Islamic Culture" textbook should be taken into account as well in promoting dialogue in the class. Some of its topics, as shown in its headings, could be added to or amended, according to the interests and needs of the students, to link the text as closely as possible to the social and cultural conditions for young Saudi people.

This gives rise to a number of points. First, some topics could be re-visited, taking into account the interests and needs of the students. Second, the information and terminology in the book could be explained and interpreted at a level suitable for the students. Third, designing technical and professional teaching programmes such as "PowerPoint" should be encouraged and exploited. Students specialising in IT could participate in this exercise. Finally, the students could be involved in providing numerical and statistical support for the topics in the textbook, as well as examples drawn from their everyday lives.

To this end, the present paper suggests several strategies. The first recommends dividing the students into groups; displaying each new topic in the first lecture each week and asking all the students to prepare points and ideas for their groups to discuss in the second lecture. Then the outcomes of the dialogues in all the groups can contribute to a dialogue at the level of the class as a whole.

The second strategy is to ask a direct question, to which students must provide a written answer within five minutes. In the second lecture, the answers to the question can be discussed and then the students split into groups to debate the question for a few minutes before the teacher summarises and concludes the discussion.

Third, a few students with different capacities and opinions can talk about a current case. Then the implications of the case can be put to them and discussed comprehensively. This will be very useful for all the students.

The fourth method is to use an internet forum, in which the participants are taught how to use this means of dialogue between students and teachers. The teacher posts a topic on the forum, which will is discussed in the next lecture. All the students are able to access the forum, to discuss the issue before the lecture and at the beginning of the lecture they should write a summary of the arguments that were presented. The students can then discuss the question and the teacher can summarise and link the result to the subject of the lecture.

The last suggestion is to replace the university book by an educational project, meaning that the students could work in groups under the supervision of academic staff in designing a new university textbook, its theoretical courses in particular. To start with, the academic staff draw up the objectives of the course. Then, they work with select students in identifying the topics for the book. Next, they divide the project into 12 weeks, equalling one semester in $\mathrm{SA}$, and divide the students into several groups of 6 or 7 members, encourage them to speak to each other and to the teachers, and suggest ways of building up the book step by step, starting by presenting ideas in the classroom and then opening the discussion to other groups to test ideas, organise the detailed ideas into chapters and at the end of the semester submit their book, together with all the others, for assessment.

\section{References}

[1] Ahmad, A. and Alwan, M. (2012) 'University Book Quality Standards', University of Assiut, Assiut, www.aun.edu.eg/faculty_arts/arabic/Developmentandreha bilitation/DevelopmentandrehabilitationPDF/FinalBook.pd f, ( 12 June 2012).

[2] Alamri, M. (2012) 'Higher Education in Saudi Arabia', Ministry of Higher Education, Saudi Arabia, www.nabusinesspress.com/JHETP/AlamriWeb11-4.pdf, ( 22 June 2013).

[3] Amankwaa, K, Hammonda, H. and Kofigahb, F. (2011) 'What is in a Textbook? Investigating the language and literacy learning principles of the 'Gateway to English' textbook series', Pedagogy, Culture \& Society, 19 (2), pp 291-310.

[4] Barnett, R. and Coate, K. (2005) Engaging the curriculum in higher education, Maidenhead: Society for Research into Higher Education and Open University Press. 
[5] Bawazeer, A. (2010) The Role of an Islamic Education Teacher in Developing Secondary Students' National Dialogue Abilities, King Abdulaziz Centre for National Dialogue, Riyadh.

[6] Bawazeer, A. (2012) The Implementation of the Capacities for National Dialogue in the University Textbook of Saudi Arabia, MRes dissertation, University of Stirling.

[7] Berg, B. (2007) Qualitative Research Methods for the Social Sciences, Boston Pearson.

[8] Bojer, M. (2010) 'The Place of Dialogue in Capacity Development', Book Chapter in; Ubels, J. \& Fowler, A. Capacity Development in Practice, London, Washington, DC: Earthscan.

[9] Bovill, C., Morss, K. and Bulley, J. (2009) 'Should Students Participate in Curriculum Design? Discussion arising from a first year curriculum design project and a literature review'. Pedagogic Research in Maximising Education, 3 (2), pp. 17-26.

[10] Boyer, E. (1996) 'The Scholarship of Engagement'. Journal of Public Service and Outreach, 1 (1), pp 11-20.

[11] Bryman, A. (2008) Social Research Methods, Oxford, Oxford University Press.

[12] Bullock, H. Mountford, J. and Stanley, R. (2001) Better Policy-Making, Centre for Management and Policy Studies, London.

[13] Carini, M., Kuh, D. and Klein, P. (2006) 'Student Engagement and Student Learning: testing the linkages'. Research in Higher Education, 47 (1), pp 1-32.

[14] Cohen, L., Manion, L and Morrison, K. (2011) Research Methods in Education, Routledge, Oxon.

[15] Dufresne, R., Gerace, W., Leonard, W., Master, J. and Wenk, L. (1996) 'Class talk A Classroom Communication System for Active Learning'. Journal of Computing in Higher Education, 7 (2), pp 3-47.

[16] Fraser, S, and Bosanquet, A. (2006) 'The Curriculum? That's just a unit outline, isn't it?' Studies in Higher Education, 31(3) pp 269-284.

[17] Friedman, K. (2002) Design Curriculum Challenges for Today's University; Conference Keynotes, www.researchbank.swinburne.edu.au/vital/access/manager /Repository/swin:11057, ( 10 October 2013).

[18] Grudens-Schuck, N. (2003) 'No Beginners: teaching participation at the graduate level', PLA Notes, 48 (12), pp11-14.

[19] Haggis, T. (2006) 'Pedagogies for Diversity: retaining critical challenge amidst fears of 'dumbing down', Studies in Higher Education, 31 (5), pp 521-535.

[20] Johnson, M. (1999) Online! Communication in the Classroom.
http://www.eric.ed.gov/PDFS/ED436802.pdf, (10 August 2013).

[21] Kajornboon, A. (2012) Using interviews as research instruments. Chulalongkorn University of Bangkok, http //www.culi.chula.ac.th/e-Journal/bod/Annabel.pdf. ( 24 February 2012).

[22] King Abdulaziz Centre for National Dialogue (2005) Dialogue Culture in Saudi Society. King Abdulaziz Centre for National Dialogue, Riyadh.

[23] King Abdulaziz Centre of National Dialogue (2012), http //www.kacnd.org/eng/, ( 24 February 2012).

[24] Kraidy, M. (2009) Reality Television, Gender and Authenticity in Saudi Arabia, University of Pennsylvania, Annenberg School for Communication.

[25] Lea, M. (1998) 'Academic Literacies and Learning in Higher Education: constructing knowledge through texts and experience', Studies in the Education of Adults, 30 (2), pp 156-171.

[26] Lea, M. (2004) 'Academic literacies a pedagogy for course design', Studies in Higher Education, 29 (6), pp 739-756.

[27] Maathuis, M. (2012) Effective teaching and classroom management is about whole child - and whole school development for knowledge, skills and human values, http //toolkit.ineesite.org/toolkit/INEEcms/uploads/1088/Effecti ve_teaching_and_classroom_management.pdf, (16 April 2012).

[28] Mahfooth, M. (2004) Political Reform and National Unity. Cultural Western Centre Casablanca.

[29] Mezirow, J. (2000) 'Learning to Think Like an Adult: Core Concepts of Transformation Theory', Book Chapter; Mezirow, J. (ed) Learning as transformation. Critical perspectives on a theory in progress, San Francisco: Jossey Bass.

[30] Morgan, H. and Houghton, A. (2011) Inclusive Curriculum Design in Higher Education: Considerations for Effective Practice Across and within Subject Areas, The Higher Education Academy, http://www.heacademy.ac.uk/assets/documents/inclusion/d isability/ICD_introduction.pdf, (20 June 2013).

[31] Nemec, P., McNamara, S. and Walsh, D. (1992) 'Direct Skills Teaching', Psychosocial Rehabilitation Journal, 16 (1), pp 13-25.

[32] Nicol, D. (2008) Assessment as a Driver for Transformational Change in HE, ESCalate newsletter Number 10 Spring, <http://escalate.ac.uk/4451> (03 June 2013).

[33] Pieczka, M. Wood, W. and Escobar, O. (2010) Dialogue in Scotland? A forum with communication practitioners", School of Arts and Social Sciences, Centre for Dialogue, Working Paper 2, Queen Margaret University Edinburgh. 
[34] Public Relations and Information Department. (2005) Manual of Definitions, King Abdul Aziz Centre for National Dialogue Riyadh.

[35] Reynolds, M., Sclater, M. and Tickner, S. (2004) 'A critique of participative discourses adopted in networked learning', EQUEL Symposium and Papers presented at the Networked Learning 2004 Conference, Lancaster University, April 5-7.

[36] Rhodes, F.H. T. (2001) The Creation of the Future. The Role of the American University. (Ithaca: Cornell University Press).

[37] Saleh, M. (1986) 'Development of Higher Education in Saudi Arabia, Higher Education, 15, pp 1723.

[38] Scandrett, E., O'Leary, T. and Martinez, T. (2005) Learning Environmental Justice Through Dialogue, PASCAL Conference Proceedings: Making Knowledge Work. Leicester: NIACE.

[39] Sfard, A. (1998) 'On Two Metaphors for Learning and the Dangers of Choosing just One'. Educational Researcher, 27(2), pp 4-13.

[40] Shor, I. (1992) Empowering education: Critical teaching for social change, London: University of Chicago Press.

[41] Silverman, D. (2006) Interpreting Qualitative Data, SAGE, Los Angeles.

[41] Spano, J. (2001) Public dialogue and participatory democracy. The Cupertino Community Project, New Jersey Hampton Press.

[42] Stewart, J. and Zediker, K. (2000) 'Dialogue as tensional, ethical practice', Southern Communication Journal, 65, pp 224-42.

[43] Swidler, L.(2012) What is Dialogue, www.institute.jesdialogue.org/fileadmin/bizcourse/Dialogu e.pdf, (03 June 2013).

[44] Wagemakers, J. Kanie, M. and Geel, A. (2012) Saudi Arabia Between Conservatism, Accommodation and Reform, Netherlands Institute of International Relations, Clingendael.

[45] Wilkinson, M. \& Scandrett, E. (2003) 'A Popular Education Approach to Tackling Environmental Injustice and Widening Participation', Concept, 13 (12), pp 11-16.

[46] Wirth, K. and Dexter, P. (2005) 'Knowledge Surveys An Indispensable Course Design and Assessment Tool'. Innovations in the Scholarship of Teaching and Learning, www.macalester.edu/geology/wirth/WirthPerkin sKS.pdf. 